\title{
How Real Are Future Events?
}

\author{
John Perry, Stanford
}

\section{Fatalism}

My main aim in this talk is to discuss McTaggart's argument for the unreality of time. I will find a flaw in his argument, but finding the flaw will lead us to the conclusion that although time is real, future events are not. I will begin, however, not with McTaggart, but with a version of an ancient argument for fatalism. By fatalism I do not mean the doctrine that we are fated, like Oedipus, to do something terrible at some point in the future, no matter what choices we make now, and no matter what happens in between. I mean the philosophical doctrine that we can do nothing at all to effect the future in any way. For most of us this will mean we are not only fated, in the first sense, to do terrible things, although perhaps not as terrible as Oedipus was fated to do, but that that even the route to these terrible deeds is not in our power to alter. I adopt as a working principle that we are entitled to the distinctions we need to avoid fatalism. I will see what these are, and then maintain that they show us the way to avoid McTaggart's argument, and that, in doing that, we will see that although there is no reason to agree with McTaggart that time is unreal, the future is, in fairly clear sense, not real.

The fatalistic argument goes like this:

1. The proposition that Hillary Clinton will be inaugurated President in 2009 is either true or false, and not both.

2. If Hillary Clinton will be inaugurated President in 2009, then that proposition is true.

3. Propositions do not change their truth-values.

4. So, if the proposition that Hillary Clinton will be inaugurated President in 2009 is true today, then it was true a year ago.

5. You cannot change the past.

6. So, if something was true a year ago, no one can do anything now, or at any time later than now, that will affect its truth-value.

7. So, if Hillary Clinton will be inaugurated President in 2009, there is nothing that she can do or Bill Clinton can do or Jeb Bush can do to- 
day, or anything that anyone else can do today, or any day in the future, to prevent it.

8. As important as Hillary Clinton is, and as important as the issue of her inauguration is, there is nothing in principle that makes this event special in terms of this argument.

9. So, if something is going to happen in the future, there is nothing anyone can do now or at any time later than now to prevent it.

The main problem with this argument, it seems to me, is that it does not recognize that many propositions, certainly including propositions about who wins elections and who is then inaugurated as president the following January, are made true or false by events, in this case, crucially, the elections that are held in November preceding the inauguration, and the events between then and the next January 20th, which may include Supreme Court decisions and the like. If it turns out that Hillary Clinton wins the 2008 U.S. presidential election and is then inaugurated in January 2009, this will be on account of events many of which will not happen until Election Day, the first Tuesday in November, 2008.

Suppose that Hillary and Bill Clinton have a big fight in late September 2008. It would be pleasant to provide details concerning what this fight might be about, but I will leave that to the audience's imagination. Feeling hurt and unappreciated, it occurs to Bill that he could make a speech in which he details every nasty thing Hillary has ever done and said, and asserts that he wouldn't vote for her for dogcatcher, much less for President, and that by doing so, he could prevent her election. He can prevent her from being inaugurated. Remembering all the good times he had in the White House, he doesn't do it, and she is elected and inaugurated. Still, if he had done it, he would have been affecting the future, not the past. He wouldn't have changed the past at all. He will not have changed the past, for he will not do anything that makes false something that has already been made true, nor does he do anything that makes true something that has already been made false.

We need to think about the truth of propositions in some way that at least does not rule out this common sense response to the fatalist argument. Even if we are hard determinists, that is, even if we believe that determinism is true and it rules out freedom, we should not be convinced by fatalism, for if fatalism is true, determinism is really quite beside the point.

It seems to me that to allow this common sense response, we need to rec- 
ognize two concepts of truth in relation to propositions. The first is a property of propositions: a proposition be true or be false, or, if you prefer, be true or false of a world. It's best to avoid tense in using this concept, hence the untensed "be". Second, events up to a certain time make a proposition true, or make it false, or leave it's truth or falsity open.

There is an important connection between these concepts:

If events up to a certain time make a proposition true (or false), then it be true (or be false).

The converse principle does not hold. There are, or at least seem to be, propositions that are not made true by events, such as the propositions of logic and mathematics and other necessary truths. If we believe that the laws of nature are contingent, and also believe that they are not merely the empirical generalizations that remain true at the end of time, but somehow structural principles that shape what happens, then they too will not be made true by events; events will conform to them, but not make them true.

From the connection, that propositions made true, be true, and what we know about being true, we know that if events up to a certain time make a proposition true (or false), events up to some other time, earlier or later, don't make it false (or true). From this, I believe, we arrive at the correct understanding of the claim that you can't change the past:

You can't do anything to make a proposition false that has already been made true, or to make a proposition true that has already been made false.

However, the following principle is not correct:

If proposition $P$ be true, no one can do anything now that will affect its truthvalue.

This is not correct, because the events that will make $P$ true may lie in the future, and someone powerful, like Bill Clinton, may well be able to do something to prevent them.

Stated carefully, the first steps of the fatalistic argument become:

The proposition that Hillary Clinton is inaugurated President in 2009 be true, or be false, but not both. 
If Hillary Clinton will be inaugurated President in 2009, then that proposition be true.

But from this, nothing too significant follows. From the supposition that the proposition be true, it does not follow that it has been made true by today, or yesterday, or will have been made true by, say, late September 2008. So it doesn't follow that, if Bill Clinton were to prevent it from being made true, by a nasty speech in late September 2008, he would have in any sense changed the past.

For discussions of determinism, a third concept is important. If a proposition is entailed by propositions that have been made true by what has happened by a certain time, together with the laws of nature, and the laws of nature are propositions that be true without having to be made true by events, then I will say that the proposition is settled by the time in question, although it has not yet been made true. So, if determinism is true, it may be settled by late September 2008, and indeed may have been settled by the time that Adam bit into the apple, that Hillary Clinton would be inaugurated as President in 2009. The question of the compatibility of human freedom and determinism is whether we can, at a given time, do things to prevent events whose occurrence is already settled. But that issue, I leave aside; I mention it only to emphasize that being settled, in this sense, is one thing, being made true is another.

Let's consider a manageable series of events, say the presidential inaugurations in the United States of the 20th century, from McKinley's in 1901 to George Bush's in 2001. ${ }^{1}$

Consider the domain of all the people who appeared on the ballot for U.S. president in the 20th century. Consider the property, being inaugurated as President of the U.S in D, where D is a year. This domain and property give us a set of atomic propositions. Some of these, like

That Carter be inaugurated President in 1976

be true of the sequence, and others, like

1 Through 1933 inaugurations were held on March 4; since then they have been held on January 20. Vice-Presidents Theodore Roosevelt, Calvin Coolidge, Harry Truman, Lyndon Johnson and Gerald Ford all became president without being inaugurated, through the death or resignation of a president. Roosevelt, Coolidge, Truman and Johnson were subsequently elected to full terms and inaugurated. 
That Carter be inaugurated President in 1980

be false of the sequence.

Each atomic proposition was made true, or was made false, by the events that occurred in the twentieth century up through March 4 of the year that is a constituent of the proposition. So, as of, say, April of 1975, a number of propositions that be true of the sequence were not yet made true or made false. As of April 1975, it had not been made true that Bush was inaugurated in 2001, nor had it been made false that Gore was inaugurated in 2001.

\section{Chronological possibility}

Now I'd like to introduce a second class of propositions, of the form:

\section{$\mathrm{X}$ in $\mathrm{D}$ can prevent $\mathrm{P}$}

where $\mathrm{X}$ is a candidate from our domain, $\mathrm{D}$ is a year in the twentieth century, and $\mathrm{P}$ is one of the original atomic propositions. Examples are:

Carter in 1980 can prevent that Reagan be inaugurated 1981

This would seem to be true if in 1980 there was some set of basic bodily movements that Carter could have made (or refrained from making), which, had he made them (or refrained from making them), other circumstances being what they were, this would have led to his winning the election of November 1980, rather than Reagan. Many analysts think that had Carter been less obsessed about the hostage situation in Iran, and not tried to micromanage the issue, he would have defeated Reagan. If they are correct, this proposition is true. It is almost certainly true

That Reagan in 1980 can prevent that Reagan be inaugurated 1981.

Reagan could have withdrawn from the race. Or, just to put some more intriguing possibility before us, he could have taken off all of his clothes in the middle of a speech, proclaimed that he was at a nudist, and would never wear another stitch, even if elected President. Or he could have divorced his wife Nancy, and married a young Hollywood starlet. I could go on, but perhaps that suffices for me to make the point. 
At each time there are propositions that have been made true, and propositions that have been made false, and, in addition, many propositions that have not been made true or made false. There is a certain kind of impossibility involved with respect to propositions that have already been made true (or false) by a certain time. There is nothing anyone can do, and for that matter, nothing that can happen, whether done by a person or simply the result of non-human causes, that will make those propositions false (or true). The kind of possibility involved is not the same as logical possibility; that is, the falsity (or truth) of these propositions does not involve a contradiction. Nor is it a matter of pure metaphysical impossibility; the propositions involved are not guaranteed to be true by whatever deep structural facts there are about the properties, relations and objects involved.

I'll call this sort of impossibility and possibility, the sort of possibility and impossibility appealed to, but misused, in the fatalist argument, chronological. Propositions that, at a given time, might still be made true by events are chronologically possible at that time, those that can no longer be made true are chronologically impossible at that time. ${ }^{2}$

\section{McTaggart's B-series and C-series}

That said, I turn to John Ellis McTaggart and his famous argument, of almost one hundred years ago, that time is unreal. He describes three series of events, which he calls the $\mathrm{C}$-series, the $\mathrm{B}$-series and the A-series. We'll put the $\mathrm{A}$-series aside for the moment, and discuss the $\mathrm{C}$-series and the $\mathrm{B}$ series. The $\mathrm{C}$-series and the $\mathrm{B}$-series both comprise all the events in history in order. They differ in that the $\mathrm{B}$-series also includes the temporal direction of the events.

Suppose that in the course of archival investigations you came across a list of leaders of some small country of which you had never heard, the Land of Woe. It looks like this:

Year 100: the reign of Elwood the Unready begins

Year 110: the reign of Gretchen the Inept begins

Year 120: the reign of Ephraim the Ignorant begins

2 J. Ellis McTaggart, "The Unreality of Time", Mind, N.S. 68, October 1908, pp. 457-474. 
You don't know whether the years listed are B.C. or A.D., however. Thus you don't know whether Elwood came before or after Gretchen. You know that Elwood's reign was next to Gretchen's, and not next to Ephraim's, but you don't know which came first. You have order, but no direction. Basically, if you can say which events came between which events, you know the order; if you can say which came first, you know the direction.

McTaggart believed that both order and direction are part of our concept of time, and that the direction of time is the direction of change. So the Cseries, plus the direction of change, should give us the B-series. McTaggart can come up with no coherent account of the direction of change, so he concluded that time is unreal.

Let us take a miniature B-series, a partial list of the history of the world, to have something manageable to think about. Let us limit ourselves again to events that are inaugurations of United States Presidents. This is, I realize, in many ways an extremely unpleasant subject to continue to think about, but I will plunge ahead nevertheless. I considered using the inaugurations of governors of California as an example for this talk; that would have provided a pleasant bond between Austria and California, since California's present governor is the beloved Austrian Arnold Schwarzenegger. However, there is a great deal of jealousy among Americans from other states, some of whom are at the conference, because California has a European governor and no other state does. So I decided it was best to stick to the example of presidents.

Since you are required to be 35 years old to be inaugurated as President, we can be sure that all of the presidents inaugurated up until 2037 are already alive. So let us limit ourselves to the succession of inaugurations that begins with Franklin Delano Roosevelt's second inauguration in 1937, continues through George W. Bush's second inauguration last January, and then continues with Hillary Clinton's two inaugurations in 2009 and 2013, Laura Bush's two inaugurations in 2017 and 2021, Chelsea Clinton's two inaugurations in 2025 and 2029, Jenna Bush's inauguration in 2033 and her twin sister Barbara's in 2037. I'm not entirely certain of these results, of course, but that's my best guess, and I am fairly confident. So: 100 years of inaugural events and 100 propositions we'll take to be of the form:

That $\mathrm{X}$ be inaugurated succeeding $\mathrm{Y}$ 
That FDR be inaugurated succeeding himself

and continuing to

That Barbara Bush be inaugurated succeeding Jenna Bush.

Let's give this series of propositions another name, say, "Dismal". If we think of Dismal as an ordered sequence of propositions then of course it cannot be changed; it is a set theoretical object, defined by its members. If all of the propositions in Dismal are true, then Dismal is a sequence of propositions that corresponds to a part of the B-series of events. I'll call such a series a "B-P series". Now, even if Dismal be a B-P series, and even if we are all powerless to do change the membership of Dismal, still someone can do something that will make it not a B-P series, by doing something that will prevent one of the propositions in it from being made true, so that the event, to which this proposition would have corresponded, does not occur. For example, Jenna and Barbara Bush might become nuns, in which case they will be prevented by Papal decree from taking part in electoral politics. That is not likely, but it could happen. Even if Dismal be a B$\mathrm{P}$ series, which requires that all the propositions in it be true, some of the events necessary to make it a B-P series have not yet happened. We, or at least powerful politicians, and their children, can do things that effect which propositions having to do with future elections; all we cannot do is affect the truth-values of the propositions that have already been made true or false.

Still, we will assume that Dismal is a B-P series and plunge on.

\section{The A-series and the D-series}

The first thing we need to do is to pull out of Dismal the information about the direction of time. This gives us a $\mathrm{C}-\mathrm{P}$ series, so I will call it Dismal $\mathrm{C}_{\mathrm{C}}$. This is a series of propositions of the form

$\mathrm{X}$ be inaugurated next to $\mathrm{Y}$.

This series contains information about which inaugurations were between which other inaugurations, but not about which came earlier and later. Now, how do we put back in what we have just taken out? To get back to a B- 
series, to get from Dismal $_{C}$ back to Dismal, we have to add information that imposes a direction on Dismal $_{C}$.

McTaggart tells us three things about what we need to add. First, it is related to temporal change, which he takes to be something we experience-or rather seem to experience, for, according to him, it turns out to be an illusion. Second, temporal change is fundamentally different from the sort of change we talk about when we say, for example, of a stretch of Hiway 4 in the Sierra Nevada Mountains, "For each town from Angel's Camp to Ebbett's Pass, the elevation above sea-level increases as the distance from the Pacific Ocean increases". I am inclined to agree with McTaggart about both of these things, although I do not think our experience of change is an illusion.

The third thing McTaggart tells us is that what we need to add to the Cseries, to add direction, is what he calls the A-series, which is the series of events ordered by whether they are in the present, past or future, and if one of the latter two, how distant. The fact that Truman's inauguration came after Roosevelt's 4th inauguration, rather than merely being next to it, and before Eisenhower's first, rather than just being next to it, consists in the fact that Roosevelt's fourth inauguration is more distantly past than Truman's, and Truman's more distantly past than Eisenhower's. This idea of McTaggart's seems to me to have been rather unfortunate, a wrong turn in the philosophy of time. I will return to what is wrong with it later, but for now I will try to give what seems to me the correct solution.

I believe that what we need to add to Dismal $_{C}$, in order to return to Dismal, is facts about chronological possibilities, which I will call the "D-P series", or, in this case Dismal $_{D}$. That is, we need to add propositions about what the chronological possibilities were at the time of Roosevelt's third and fourth inaugurations, Truman's inauguration, and so forth, right down through the chronological possibilities at the time of Bush's first inauguration, Bush's second inauguration, Hillary Clinton's first inauguration, and beyond.

I am allowing myself the concept of simultaneity in time, for as I understand McTaggart, this allowed in the $\mathrm{C}$-series. Events $\mathrm{X}$ and $\mathrm{Y}$ occur at the same time if there is no event between them, and we can have this information, even if we do not have the information about the direction of events. So we can add Dismal $_{D}$ to Dismal $_{C}$, giving us a sequence of propositions about the occurrence of inaugurations and the chronological possibilities and impossibilities at the times those inaugurations occurred. 
During his third term Roosevelt's vice-president was Henry Wallace, a Democrat from the left wing of the party, perhaps correctly called, as he was by many Republicans, a socialist. Had Roosevelt chosen Wallace for his running mate for the 1944 election, as he certainly could have, then it seems that either of two things would have happened. One is that Thomas Dewey, the Republican candidate in 1944, would have defeated Roosevelt. The other is that Roosevelt would have won, and Wallace rather than Truman would have succeeded to the Presidency in 1945 when Roosevelt died. If either of these courses of events had occurred, then it is virtually certain that Truman would never have been President, for he was a amiable Missouri Senator with no presidential ambitions. So, it seems that at the same time as Roosevelt was inaugurated for his third term in 1941, it was chronologically possible that Truman not be inaugurated in 1949, as he in fact was, having served out the rest of Roosevelt's fourth term and having defeated Dewey in 1948. However, by the time of Eisenhower's first inauguration in 1953, it was no longer chronologically possible that Truman not be inaugurated in 1949.

When we add true propositions about chronological possibilities for other inaugurations to Dismal $_{C}$, a clear pattern emerges, that gives us two clear directions, one of which is the direction of temporal change. As we move one direction through augmented Dismal $_{C}$, possibilities will increase, and as we move another direction, possibilities will decrease. The possibility that Gore be inaugurated in 2001 is present at Roosevelt's second inauguration in 1937, and at every subsequent inauguration through Clinton's second inauguration in 1997. Then it disappears, sad to say. The direction of time, and of change, is the direction of decreasing possibilities. If we confine ourselves to any finite subset of the contingent propositions that be true, more and more will be made true, and more and more rendered impossible, as we consider events that are later in time, and fewer and fewer will have been made true, and fewer and fewer rendered impossible, as we consider events that are earlier in time.

\section{Change and the $\mathrm{D}$-series}

I now turn to the question of whether the D-series meets McTaggart's requirements for what needs to be added to a $\mathrm{C}$-series to get a $\mathrm{B}$-series, namely, whether it is something that characterizes our experience of temporal change, and is not merely a matter of change along a dimension. 
Angels Camp, Murphys, and Arnold are three towns one drives through, as one travels east along California hiway 4, which runs from the Bay Area through the Sierras to Nevada. Consider the facts about the elevations above sea level of these three towns, roughly 1500 feet, 2500 feet, and 3500 feet. One experiences this change in elevation of towns along hiway 4, relative to the distance from the Pacific Ocean, as one travels along the hiway. Each of these facts, by itself, does not necessitate the others; Angels Camp could be at 1500 feet, even if Murphys were not at 2500 feet, and vice versa, for example. On the other hand, if we travel along hiway 4 from west to east, then by the time we get to Murphy's we have eliminated the possibility that Angels Camp has any elevation other than 1500 feet, and that Murphy's has any elevation other than 2500 feet, but not have eliminated the possibility that Arnold has some elevation other than 3500 feet. So there is a progression, a change, in what is possible, as we travel from east to west.

This is, however, much different from chronological possibility. For one thing, the change in what is possible, in this case, has to do with what the subject knows; it is a matter of epistemic possibility. Related to this, the situation is reversible; if you travel from east to west, then when you get to Murphy's it will not be possible that Arnold has any elevation other than 3500 feet, but it will be possible that Angels Camp has some elevation other than 1500 feet. Chronological possibility is not simply a matter of epistemic possibility, and it is not reversible in this way.

Let's return to our friend Bill Clinton, late September 2008, contemplating whether to make a speech that will destroy Hillary Clinton's chances of being inaugurated the following January. He might think that it is possible for him to destroy her chances; it is something that he can do; it is a possibility for him; it is up to him. On the other hand, at that point in time, it is not possible for him to destroy her chances for being nominated, which will have happened in Summer of 2008. That was once a possibility, say in the early days of the Democratic Convention and before, but it is no longer a possibility by early September 2008. In other words, Clinton, is aware of chronological possibilities, and chronological impossibilities, as all of us are. As we experience change, we experience the decrease in chronological possibilities, and the increase in chronological impossibilities. Opportunities, once missed, are gone. The direction in which the chronological impossibilities increase and the chronological possibilities decrease is the direction of change as we experience it. 
As we experience change, it involves events occurring, which we perceive and participate in, which make it the case that various propositions are true or false, and leave no possibility of our doing anything, or anything happening, that will make them otherwise. Past events and future events play different roles in our lives, cognitive, emotional, and practical, all connected to our sense of chronological possibility. We regret the past, and try to make up for it, or cover it up, or change its consequences. But we do not try to change the past itself. We try to shape the future, to make some events more likely to occur, and others less likely to occur. We remember the past; we anticipate the future. Everyone seems to agree about this. People move from west to east, and east to west, and as they do they remember where they have been, and anticipate the experience of what they have yet to encounter. But all are anticipating the future, and remembering the past. No one moves from future to past, trying to affect the past, and remembering the future.

So, I conclude, chronological change meets McTaggart's requirements, and that by augmenting the Dismal $_{C}$ with Dismal $_{D}$ we have returned to our starting point, Dismal, a B-P series, and done what McTaggart thought could not be done. But you won't be convinced yet, not until we have discussed the A-series, and some other issues about the B-series.

\section{McTaggart and the A-series}

McTaggart thought that you had to add the A-series, the one that divides events into past, present, and future, to the $\mathrm{C}$-series to get the $\mathrm{B}$-series. $\mathrm{He}$ did not think that there was a coherent way to do this, and so concluded that time was unreal; that is, we have a clear concept of what time would have to be, something characterized by the combined $\mathrm{C}$-series and $\mathrm{A}$-series, but we see clearly that there can be no such thing.

So according to McTaggart, the fact that Truman's inauguration came after Roosevelt's 4th inauguration, rather than before it, or merely being next to it, consists in the fact that Roosevelt's 4th inauguration is further in the past than Truman's.

I cannot see much merit in McTaggart's idea. Suppose I say now, truthfully if sadly, "George W. Bush's 2 nd inauguration is past". What fact makes that true? A pretty reasonable theory says that my utterance, call it $u$, is true simply because George Bush's 2nd inauguration precedes $u$, the utterance itself. So, if we want to put the fact that I seem to be getting at when I say 
"George Bush's 2nd inaugural is past", into Dismal ${ }_{C}$, we ought to add the proposition to that George Bush's 2nd inauguration precedes $u$. But that proposition is already a $\mathrm{B}-\mathrm{P}$ series proposition. If we are going to add $\mathrm{B}$ series proposition to Dismal $_{C}$ in order to get to Dismal, we may as well simply jump back to Dismal and be done with it.

I should point out that one can agree with this, even if one thinks, as I do, that David Kaplan's theory is correct, in saying the proposition that George Bush's 2nd inauguration precedes $u$ is not the proposition expressed by my utterance. According to his theory, the proposition expressed by my utterance of "George Bush's inauguration is past", is not a proposition about my utterance itself, but (roughly) a proposition about the time $t$, the time at which my utterance occurs, to the effect that George Bush's inauguration precedes $t$. This proposition would be true, even if I had not made the utterance $u$. If we trace Kaplan's analysis through, we see that my utterance will be true iff George Bush's election precedes it, for only under those conditions will it express a proposition that is true. Moreover, the expressed proposition, that George Bush's inauguration precedes $t$, is also a $\mathrm{B}$-proposition, not a C-proposition.

I don't mean to imply that McTaggart somehow missed the fact that adding these propositions to the $\mathrm{C}$-series would be begging the question. He did not think that the words "past", "present", and "future" were basically getting at relations to the utterances of sentences containing them, but that they get at properties of events; indeed, he thought that the passage of events from future to present, and present to past, was the essence of temporal change. He thought that to find real temporal change, we needed to find some temporal way in which the B-series changes, that corresponds to our subjective sense of events passing from the future, into the present, and then into the past.

But, McTaggart thought, there can be no change in the B-series. The $\mathrm{B}$-series contains all the events, and their temporal relations, which never change-as he puts it,

If $\mathrm{M}$ is ever earlier than $\mathrm{N}$, it is always earlier.

So, our concept of time demands that the B-series is the A-series added to the $\mathrm{C}$-series; but then the $\mathrm{B}$-series will have to involve events changing from future to present to past; but this makes no sense.

So we need to consider whether we have evaded this conundrum. Does 
my account of what we need to add to the $\mathrm{C}$-series to get a B-series imply a sort of change in the $\mathrm{B}$-series that makes no sense?

\section{The future is unreal}

As I just said, early in his discussion, McTaggart says,

If $\mathrm{M}$ is ever earlier than $\mathrm{N}$, it is always earlier.

It seems to me this is a mistake. Consider Bush's 2nd inauguration. It has happened, while Hillary Clinton's first inauguration has not happened yet. Is it correct to say that Bush's 2nd inauguration is earlier than Hillary Clinton's first inauguration? Certainly after Hillary Clinton's first inauguration we can say that Bush's inauguration was earlier than it. But was it earlier, before Hillary's first inauguration happened? Is it now earlier than her inauguration?

It seems to me that Hillary Clinton's inauguration is not now later than Bush's second inauguration, because Hillary Clinton's inauguration does not yet exist. By Hillary Clinton's inauguration I mean the concrete event, not a description of it, or an abstract object that characterizes it. The concrete event, it seems to me, has no reality at all until it happens, even if the propositions that say that it will happen be true, or for that matter, even if it is settled, in the sense I adumbrated in the brief discussion of determinism early on, before it happens. The concrete event has no existence, no reality, until it happens.

My argument for this is that the status of the events that will occur, before they occur, is the same as the status of the events that might occur in their stead, but will not. All are possibilities, not realities, before one of them occurs; it becomes real, the others do not.

According to the picture I have put forward, at each time there is a future which is characterized by a number of contingent possibilities or propositions, none of which have been made true at that time, and all of which might still be made true, but only one of which will be made factual: a garden of forking paths, as Borges puts it. Then, at a later time, some of those possibilities will be eliminated or made false. Now the simplest explanation, for the legitimacy of this picture, as far as I can see, is that at each time all of the possibilities for the future have the same status: they are mere possibilities. That is, until an event happens (and so makes the proposition 
according to which it happens, true), the event is a merely possible event, and not a real event. And by saying it is merely a possible event, I mean to say, basically, that it is not an event at all; there are descriptions, and abstract types, that will denote or characterize the event once it exists to be denoted or characterized. But there is no concrete event.

Consider, for example, the two events, Hillary Clinton's inauguration in 2009 and Joseph Biden's inauguration in 2009. Those are both, as I speak, possibilities, as these seem to be the two leading contenders for the Democratic nomination. We assume however that Clinton will be inaugurated, and Biden will not be. If so, there is not now, and never will be, a concrete event correctly called "Biden's inauguration in 2009". The lack of such a concrete event does not impede us in any way in describing the possibilities that there are at the present time, including the possibility that Biden wins and is inaugurated.

Now if Biden were to win the nomination, and the election, and be inaugurated, we would definitely feel the need to recognize a concrete event. The event in question would be visible, televised, and consequential. It would have effects, and these only concrete events can have. But we won't miss the concrete event of his inauguration if he does not win. By the same token, we will not need the concrete event of Hillary Clinton's inauguration until she wins the nomination and election and is inaugurated. Until then descriptions of it and abstract types that characterize it will serve all of our needs in language and thought.

I conclude that future events are not real; they do not exist, until they occur. Until that time they, the concrete events themselves, are not after the other events occur before them. As Broad put it,

Let us take McTaggart's example of the death of Queen Anne, as an event which is supposed to combine the incompatible characteristics of pastness, presentness, and futurity. In the first place, we may say at once that, on our view, futurity is not and never has been literally a characteristic of the event which is characterised as the death of Queen Anne. Before Anne died there was no such event as Anne's death, and "nothing" can have no characteristics. After Anne died the sum total of existent reality does contain Anne's death, but this even then has the characteristic of pastness. No doubt I can say “Anne's death was future to William III”. But I simply mean that, so long as William III was alive, there was no event characterised as the death of Anne; and that afterwards, as the sum total of exist- 
ence increased by becoming, it contained both the events of William's life and the event of Anne's death. Anne's death succeeded William's life so soon as Anne's death existed at all, and it succeeds it henceforth for ever; but it does not succeed it while William was alive, because it had not become, it was not anything, and therefore could not have any characteristics or stand in any relations ...". 3

And that means, I think, that as I speak, there are no concrete events at all that are referred to or denoted by the two descriptions "Hillary Clinton's inauguration in 2009" and "Joseph Biden's inauguration in 2009". There are two event descriptions, or event types; that is, two linguistic objects and two abstract objects. Some day, if things turn out the way I predicted, one of these linguistic objects will refer or describe a concrete event, which will be of the type in question.

So, as confident I am of her victory and inauguration, at the present time, still, there is, in the strict and metaphysical sense, no event that fits the description "Hillary Clinton's 2009 inauguration" any more than there is an event that fits the description "Joseph Biden's 2009 inauguration". Both are chronologically possible, which is to say that it hasn't been ruled as of 2005, when I write, that events that will meet these descriptions occur in 2009.

\section{Does the B-series change?}

But does not this mean that the B-series changes? How can the B-series change, if all of the changes are in the B-series?

If the B-series is an actual succession of concrete events, it does change; it grows, and we see it do so, when we observe change. If this is what we mean by "the B-series" then it is not an abstract set-theoretical object, but an actual process, the all-inclusive process, of things happening.

If by "the B-series" we a set theorietical sequence of concrete events, then it seems to me our idea is incoherent. Right now, in 2005, lots of events that will happen have not yet happened. For example, Hillary Clinton's inauguration has not yet happened. We can talk about such events using bits of language like "Hilary Clinton's inauguration" or we can model them with suitably constructed abstract objects to serve as proxies. We can use these

3 C.D. Broad, Scientific Thought, London: Routledge and Kegan Paul, 1923, pp. $79-80$. 
bits of language or abstract objects to build (or imagine building) models of various possible candidate B-series, and we can describe one of them as the unique one that contains a description of or a proxy for all that ever will occur. But the B-series of events itself doesn't exists until all its constituents exist, and they don't all exist yet.

If by "the B-series" we mean the sequence of descriptions or abstract proxies that we can use to model events, or a set-theoretical sequence of propositions of the sort we have considered earlier, that will uniquely fit what happens as long as things keep happening, then it is fair to say the $\mathrm{B}$-series does not change. But its status may change. At the present time, when the results of the 2008 election are still slightly in doubt, there are a number of such unchanging abstract objects, sequences of propositions say, that are possible B-series: they fit everything that has happened so far. Some of them contain the proposition that in 2009 Hillary Clinton is inaugurated, some of them contain the proposition that Joseph Biden is inaugurated, and I suppose still others contain the propositions that Condoleezza Rice, or Jeb Bush, or John McCain, or even, given the possibility of a constitutional amendment, Arnold Schwarzenegger, is inaugurated. None of these sequences will ever contain different propositions than it does, but most of them will change, as time passes, in losing the status of possible B-series.

In concrete terms, our experience of change, and of the passage of time, is the experience new events coming into existence, and old possibilities being eliminated. In abstract terms, it is seeing propositions being made true and false, and sequences containing those propositions ceasing to be possible B-series.

\section{Conclusion}

I have argued that to avoid fatalism we need to recognize a distinction between propositions that have been made true as of a given time, and propositions that be true, in the sense that they have been or will be made true. The "be" in the expression of the second concept is tenseless; it is the way we ought to talk about what goes on in "possible worlds", including our own, when we are not describing them from a time within them, or abstracting from that time. The principle appealed to in the fatalistic argument I considered is properly couched with the first concept: we cannot now, or at any time in the future, make a proposition true that has already been made false, 
or make a proposition false that has already been made true. But this principle does not lead to fatalism.

Given this distinction, it is natural to recognize chronological possibility as the sort of possibility that is appealed to in the principle just stated. Chronological possibilities change with time; they are eliminated as one among a number of possible events that could have happened, does happen. If we characterize the change that is peculiar to time, what is sometimes called "temporal becoming", in terms of this elimination of chronological possibilities, rather than in terms of McTaggart's "A-series", then we can, I claim, answer the challenge that is at the heart of his argument for the Unreality of Time, and explain what must be added to the "C-series" to get to the "Bseries". The A-series, for all the ink that has been spilled discussing it, is a bit of a red herring.

Now a couple of final words. First, insofar as I have made any progress here it is due to conversations with Thomas Hofweber; we hope someday to publish a paper on the important differences between events, representations of them, and models of them which will explain and put in their proper places all of the many insights that have accumulated in discussions of McTaggart's argument. But I have probably not gotten these matters quite clear, or quite straight, in this paper.

Second, I was privileged to have Nathan Oaklander as the chair of the session at which this paper was presented. Oaklander holds a version of the B-theory, the theory I have believed to be correct most of my philosophical life, although I have never felt particularly comfortable with it. In conversations in person and by email Oaklander has helped me express my views more clearly, and tugged me a bit towards my old view. I am very thankful to him for his help, and for his fine writings on time.

Although I do believe the view I have developed here to be correct, or at least on the right track, as I write, I am very conscious of how difficult the philosophy of time is. Even my hero Broad, Oaklander tells me, held five different theories of time over his career. This is my second. I am not all that confident it will be the last. 